\title{
Un caso de miasis humana por Cochliomyia hominivorax (Diptera: Calliphoridae) asociado a pediculosis en Mendoza, Argentina
}

\author{
ELENA C. VISCIARELLI*, SUSANA H. GARCÍA*, CRISTINA SALOMÓN**, \\ CLAUDIO JOFRÉ** y SIXTO R. COSTAMAGNA*
}

\section{A CASE OF HUMAN MYIASIS BY Cochliomya hominivorax (DÍPTERA: CALLIPHORIDAE) ASSOCIATED WITH PEDICULOSIS IN MENDOZA, ARGENTINA}

The aim of the present investigation was to identify the fly producing myiasis in a patient with pediculosis. The patient was a male adult with a severe Pediculus humanus capitis' infestation and a lesion on his head containing larvae. Examination of these larvae revealed that they were Cochliomyia hominivorax. In this clinical case, the post-scratch lesions were infected with $\boldsymbol{C}$. hominivorax' $s$ larvae. It is the first time that the myiasis-pediculosis association has been mentioned in the literature.

Key words: Human myiases, Cochliomyia hominivorax. Pediculus humanus capitis, Pediculosis.

\section{INTRODUCCIÓN}

Miasis es la lesión producida por larvas de dípteros ciclorrafos en el hombre o animales donde se nutren en forma parásita de tejidos vivos o muertos, produciendo invasión y destrucción tisular.

Se clasifican según las larvas que las producen y las localizaciones y formas clínicas en el hombre; así las miasis pueden ser producidas por larvas biontófagas o necrobiontófagas. Las primeras invaden tejidos vivos o cavidades naturales y son parásitos obligados; las segundas colonizan lesiones preexistentes y son parásitos accidentales. Según el tipo de lesión o localización las miasis se dividen en cutáneas, cavitarias o traumáticas y gastrointestinales ${ }^{1}$.
Se describen los siguientes factores de riesgo: exposición de úlceras y hemorroides ${ }^{2}$, infecciones bacterianas de heridas o cavidades naturales ${ }^{3}$, mala higiene personal ${ }^{4}$, tareas relacionadas con la cría de animales de campo ${ }^{5}$, conductas asociadas al alcoholismo como insensibilidad y costumbre de dormir al aire libre ${ }^{6}$, ingesta de alimentos contaminados 7 y pacientes con funciones físicas y/o mentales disminuidas hospitalizados en nosocomios que carecen de condiciones higiénicas adecuadas.

Dentro de los factores de riesgo que aún no han sido mencionados se encuentran las lesiones que se producen como consecuencia del rascado en pacientes con pediculosis y extremo descuido del aseo personal.

El objetivo del presente trabajo fue describir

\footnotetext{
* Cátedra de Parasitología Clínica, Universidad Nacional del Sur, San Juan 670 (8000) Bahía Blanca. Argentina. Te: 51-0291-4595101.FAX: 51-0291-4595129.E-mail: evisciar@criba.edu.ar

** Área de Parasitología. Departamento de Patología. Facultad de Ciencias Médicas. Universidad Nacional de Cuyo. Parque General San Martín. (5500) Mendoza. Argentina.
} 
Un caso de miasis humana asociado a pediculosis - E.C. Visciarelli et al.

un cuadro de miasis en un paciente con un cuadro avanzado de pediculosis, realizando la determinación taxonómica de las larvas extraídas de la lesión.

\section{CASO CLÍNICO}

Paciente de 36 años de edad, de sexo masculino, oriundo de Maipú, zona urbana de la ciudad de Mendoza, Argentina. Empleado de campo, actualmente desocupado, de condición socioeconómica baja. Al momento de la consulta presentaba importante descuido de su aseo personal, malnutrición, pediculosis y una lesión en la región parietal derecha de la cabeza, cubierta con cabellos que formaban una costra con secreciones serosanguinolentas. La lesión presentaba $5 \mathrm{~cm}$ de largo, por $3 \mathrm{~cm}$ de ancho y 2,5 cm de profundidad; de bordes netos, forma irregular, lecho sangrante y múltiples túneles en la base de la herida, de donde emergieron gran cantidad de larvas, más de 40 , de diferente tamaño. Se procedió a la recolección y separación de las larvas en dos grupos: las más grandes (clasificadas luego como larvas III) se fijaron en alcohol $70^{\circ}$ y las más chicas (clasificadas como larvas I y II) se colocaron en un frasco con un trozo de carne para su alimentación y posterior evolución. A las 24 horas se colocó tierra en el frasco para que pudieran empupar. Pasadas todas las etapas evolutivas emergieron los adultos.

Las larvas III que estaban en la solución fijadora se procesaron según la técnica para la confección de preparaciones microscópicas ${ }^{9}$. Con un bisturí se le cortó su segmento corporal número 12 y se colocó con su extremo caudal hacia arriba en un portaobjetos para permitir la observación al microscopio óptico de las placas estigmáticas. El resto del cuerpo larval fue montado en sentido lateral entre porta y cubreobjetos para la observación de los espiráculos anteriores y el esqueleto cefalofaríngeo.

Las larvas presentaban externamente las típicas bandas de espinas grandes en su cutícula, visibles a simple vista y triangulares, razón por la cual son denominados "gusanos tornillo" o "screw-worm". Internamente se observaron las siguientes características diagnósticas de larvas III: espiráculos anteriores con prolongaciones digitiformes, espiráculos posteriores con tres hendiduras y un peritrema incompleto con indicios de botón, troncos traqueales fuertemente pigmentados y aparato cefalofaríngeo con brazos dorsales más largos que los ventrales.

De acuerdo a la descripción de las larvas y a los caracteres morfológicos de los adultos obtenidos en el laboratorio se determinó, utilizando claves taxonómicas, que el material extraído de la herida del paciente se correspondía con Cochliomyia hominivorax.

El cuadro fue resuelto provocando la salida de las larvas y posterior extracción de las mismas, desinfectando la lesión, tratando la pediculosis y con el uso de antibiótico.

\section{DISCUSIÓN}

Los cuadros de pediculosis, producidos por Pediculus humanus capitis, tienen como síntoma clínico un intenso prurito que ocasiona enérgico y continuo rascado de la región afectada. Esto provoca heridas en el cuero cabelludo que son puerta de entrada a otras infecciones en pacientes con acentuado descuido del aseo personal. En este caso clínico, las lesiones postrascado se sobreinfectaron con larvas de $C$. hominivorax, siendo la primera vez que se menciona en la literatura la asociación miasis-pediculosis.

Se destaca una vez más, el papel de $C$. hominivorax como productora de miasis humana y la importancia de realizar un diagnóstico rápido y específico dada la agresividad de sus larvas biontófagas que son capaces de destruir tejido óseo ${ }^{10}$.

\section{RESUMEN}

Un paciente, adulto, masculino, presentaba al momento de la consulta una severa infestación por Pediculus humanus capitis y una lesión en la cabeza de donde emergían larvas. El material extraído de la herida del paciente correspondió a Cochliomyia hominivorax. En este caso clínico, las lesiones producidas por el rascado del propio paciente permitieron atraer moscas $C$. hominivorax las que depositaron sus huevos en ellas de donde eclosionaron sus larvas que ocasionaron la miasis cutánea.

\section{REFERENCIAS}

1.- DEL PONTE E. Manual de Entomología Médica y Veterinaria Argentinas. Ed. Librería del Colegio. Buenos Aires. Argentina, 1958. 
2.- VELASCO E, RAMÍREZ M, RAMÍREZ E, CORTIZAS A. Miasis Anal Pren Med Argent 1974; 61: 775.

3.- MAZZA S, BASSO R. Miasis de úlcera crónica de pierna por Sarcophaga barbata y Cochliomyia hominivorax. Investigaciones sobre dípteros Argentinos, Misión de Estudios de Patología Regional (M.E.P.R.A) 1939. Publicación $\mathrm{N}^{\circ}$ 41: 47-54.

4.- JÖRG M. Miasis anal y consideraciones generales del parasitismo por larvas de mosca. Pren Med Argent 1976; 63: 47-51.

5.- BACIGALUPO J, VILLAMIL C. Miasis humana por Oestrus ovis, Linneo, 1761. Primeras Jornadas de Entomoepidemiología Argentina 1959; 2: 8336.

6.- BASSO R. Frecuencia y naturaleza de las miasis en Mendoza. Observación $\mathrm{N}^{\circ} 7$ y $\mathrm{N}^{\circ} 10$. Investigaciones sobre Dípteros Argentinos. Misión de Estudios de
Patología Regional Argentina (M.E.P.R.A) 1939; Publicación $\mathrm{N}^{\circ}$ 41: 61-5.

7.- KUN M, KREITER A, SEMENAS L. Myiasis gastrointestinal humana por Eristalis tenax. Rev Saúde Pública 1998; 32: 367-9.

8.- MIELKE U. Nosocomial Myiasis. J Hosp Infect 1997; 37: 1-5.

9.- MAZZA S, JÖRG M. Cochliomyia hominivorax (Coq. $)=$ americana C. y P., Estudio de sus larvas y consideraciones sobre miasis. Investigaciones sobre Dípteros Argentinos. Misión de Estudios de Patología Regional Argentina (M.E.P.R.A) 1939; Publicación $\mathrm{N}^{\circ}$ 41: 3-46.

10.- CALDERÓN O, RIVERA P, SÁNCHEZ C, SOLANO M. Cochliomyia hominivorax (Díptera: Calliphoridae) como agente causal de miasis aural en un niño de Costa Rica. Parisitol al Día 1996; 20: 130-2.

\section{ATENCION A LOS AUTORES}

PARA AGILIZAR LA EDICION DE PARASITOLOGIA LATINOAMERICANA, LOS AUTORES DEBERAN ENVIAR POR CORREO LOS ARTICULOS CIENTIFICOS GRABADOS EN UN DISKETTE DE $31 / 2$ EN WORD 6.0 O SUPERIOR JUNTO CON EL MANUSCRITO DEL TRABAJO A PUBLICAR O ADJUNTARLO POR CORREO ELECTRONICO A halcaino@uchile.cl 